\title{
Risk of burnout among radiographers in a large tertiary care hospital in Saudi Arabia
}

\author{
Khalid Alyousef*1, Hatim Alharbi ${ }^{2}$, Rashed Alkharfi ${ }^{2}$, Winnie Philip ${ }^{2}$ \\ ${ }^{1}$ King Abdulaziz Medical City, National Guard Health Affairs, Riyadh, Saudi Arabia \\ ${ }^{2}$ King Saud Bin Abdulaziz University for Health Sciences, Riyadh, Saudi Arabia
}

Received: April 24, 2019

DOI: $10.5430 /$ jha.v8n $4 p 38$
Accepted: June 26, 2019

Online Published: July 11, 2019

\begin{abstract}
Objective: Radiographers are known to be at increased risk of burnout due to the emotionally taxing interactions that they have with their patients on a daily basis. The aim of this study was to assess the risk of burnout among radiographers in a large tertiary care hospital in Saudi Arabia.

Methods: This was an observational, cross-sectional study using the Maslach Burnout Inventory-Human Services Survey (MBI-HSS). This tool has been extensively tested and validated. 150 full-time radiographers at King Abdulaziz Medical City (KAMC), Riyadh, Saudi Arabia were invited. Trainees, interns and on job trainees (OJT) were excluded to ensure sample homogeneity.

Results: 150 participants were invited to participate in the questionnaire with response rate 142 (95\%). 70 participants (49\%) were male and $72(51 \%)$ female. Maslach Burnout Inventory-Human Services Survey subscale results: The mean $( \pm S D)$ score for emotional exhaustion, depersonalization and personal accomplishment were $21.44( \pm 13.0), 8.12( \pm 6.99)$ and $35.63( \pm 8.59)$ respectively. Moderate to high risk of burnout for emotional exhaustion, depersonalization and personal accomplishment were reported in $67 \%, 52 \%$ and $58 \%$ of participants respectively.

Conclusions: $67 \%$ of radiographers were at moderate to high risk of burnout for emotional exhaustion, $52 \%$ for depersonalization and $58 \%$ for personal accomplishment. Policymakers should take necessary steps to recognize factors contributing to staff burnout and take appropriate steps to improve the work environment.
\end{abstract}

Key Words: Burnout, Radiographer, Work environment, Stress

\section{INTRODUCTION}

Burnout can be defined as the impact of unrelieved stress on individuals' reactions. ${ }^{[1]}$ Its consequences may contribute to the deterioration of psychological and physiological functions, reduce morale, productivity and increase absenteeism, job turnover, alcohol or drug abuse. ${ }^{[2-7]}$ Burnout may directly or indirectly affect patient outcomes. A study found a significant association between high burnout scores and poor culture of safety scores. ${ }^{[8]}$ Multiple studies showed that rotating shift assignment workers were more prone to burnout and may risk the safety of both health care providers and patients. ${ }^{[9-16]}$ The Maslach Burnout Inventory-Human Services Survey (MBI-HSS) is a validated tool to assess the prevalence of burnout in three sequential subscales, namely: emotional exhaustion (reduction in emotional resources and energy), depersonalization (negative feelings and insensitivity towards service recipients) and lack of personal accomplishment (negative impression of person's work). ${ }^{[17]}$

\footnotetext{
*Correspondence: Khalid Alyousef; Email: YousefK@ngha.med.sa; Address: King Abdulaziz Medical City, PO Box 22490 Riyadh 11426, Kingdom of Saudi Arabia.
} 
There are many factors that have been shown to contribute to burnout among health care providers, including gender, stage of life, work-life relationships, age group and workplace environment. ${ }^{[18-31]}$ Years of experience can make health care providers less susceptible to burnout. ${ }^{[32,33]}$ A significant correlation has been shown between burnout and working condition. ${ }^{[33-43]}$ Individuals who care about other people, performing ideal service to others, who work with high expectations, and who deal with other people's problems are more susceptible to burnout. ${ }^{[44]}$ Prevalence of burnout and the effect of public's point of view has been shown to be closely correlated. ${ }^{[45]}$ Radiographers who have many responsibilities toward patients, colleagues, referring physicians, and radiologists are exposed to chronic stress and occupational burnout. ${ }^{[46,47]}$ Moreover, radiographers are expected to do more with fewer resources which increase susceptibility to acquiring burnout. ${ }^{[46]}$ Staff turnover at King Abdulaziz Medical City (KAMC) has been increasing recently as reported by manpower status reports. This could be very well attributed to staff burnout. Burnout among health care providers has been the subject of many studies. However, there is lack of data reporting burnout among radiographers in Saudi Arabia. This study is the first to assess the risk of burnout in a large tertiary care hospital in Saudi Arabia.

\section{MATERIALS AND METHODS}

This study was conducted at KAMC, a large tertiary care hospital with a bed capacity of 1,500 including the largest trauma care center in Saudi Arabia. It employs more than 150 radiographers. Full time radiographers are required to work a total of 45 hours per week with 2 days off. The radiology department at KAMC is a very large and busy department, performing more than 300,000 procedures per year. An observational, cross-sectional study using the MBI-HSS was conducted. The MBI-HSS tool has been extensively tested and validated. ${ }^{[17,48]}$ A license was purchased from Mind Garden Incorporation to administer the survey tool. The tool consists of 22 questions. An additional 4 multiple choice questions were added to the tool. These 4 questions covered gender, coping techniques, factors that affect the relationship to the work and what the participants have considered in the past 12 months. MBI-HSS questions measure the 3 stages of burnout syndrome in terms of emotional exhaustion (9 items), depersonalization (5 items) and lack of personal accomplishment (8 items). The manual scoring key was used to classify participants into low, moderate, or high risk of burnout (see Table 1). The MBI-HSS questions were written as personal feelings about the subjects. The answers were as how often the participants experienced these feelings on a 7-point Likert type scale starting from never (0) to every day (6). A higher mean score indicated greater burnout for emotional exhaustion and depersonalization. On the other hand, in personal accomplishment, higher burnout is associated with less mean score. We administered the MBI-HSS as an online survey using Mind Garden's Transform System $\mathbb{R} .{ }^{[49]}$ 150 full time radiographers were invited to participate in this study. Trainees, interns and on job trainees (OJT) were excluded to ensure sample homogeneity. The participants were assigned in different areas within the department such as General X-ray, Computed Tomography (CT), Magnetic Resonance Imaging (MRI), Vascular Imaging Radiology (VIR), Ultrasound (US) and Nuclear Medicine (NM). Participation was voluntary and all personal information was anonymous. Participants were told that the study was about their personal experience in relation to their work in the radiology department, without using burnout term to avoid their sensation to the topic. Data collection was performed between 28 February to 16 April 2018 (48 days). The collected data were entered in MS Excel and was transferred to SPSS (Statistical Package for Social Sciences version 25 SPSS, Inc., Armonk, NY) for statistical analysis. Institutional Review Board (IRB) approval was acquired from King Abdullah International Medical Research Center (KAIMRC). Mean and standard deviation $(S D)$ for the three stages were obtained.

Table 1. Categorization of MBI-HSS scores

\begin{tabular}{llllll}
\hline MBI Overall Sample & Number of items & Max. Score & Low & Moderate & High \\
\hline Emotional exhaustion & 9 & 54 & $\leq 16$ & $17-26$ & $\geq 27$ \\
Depersonalization & 5 & 30 & $\leq 6$ & $7-12$ & $\geq 13$ \\
Personal Accomplishment & 8 & 48 & $\geq 39$ & $32-38$ & $\leq 31$ \\
\hline
\end{tabular}

\section{RESUlts}

150 full time radiographers working at KAMC were invited via e-mail to participate in our survey. 142 radiographers completed the survey with a response rate of $95 \%$. Seventy participants (49\%) were male and $72(51 \%)$ were female.

Published by Sciedu Press
The mean $( \pm S D)$ score for emotional exhaustion, depersonalization and personal accomplishment were 21.44 ( \pm 13.0), $8.12( \pm 6.99)$ and $35.63( \pm 8.59)$ respectively. Our results showed slightly higher mean of emotional exhaustion (21.44) comparing with MBI norms (21.0), personal 
accomplishment (35.63) comparing with MBI norms (34.6) and slightly lower mean of depersonalization (8.12) comparing with MBI norms (8.7) (see Table 2). However, the differences were not significant for all three stages. The percentage of radiographers who were at moderate to high risk of burnout for emotional exhaustion, depersonalization and personal accomplishment were $67 \%, 52 \%$ and $58 \%$ respectively (see Table 3 ). The mean score for male was 22.2 $( \pm 11.71), 9.5( \pm 7.04)$, and $35.6( \pm 7.85)$ for emotional exhaustion, depersonalization, and personal accomplishment respectively. Also, female scores were 20.6 ( \pm 11.00$), 6.75$ $( \pm 6.13)$, and $35.6( \pm 8.66)$ for emotional exhaustion, depersonalization and personal accomplishment respectively. In emotional exhaustion subscale, all radiographers working in US section were at moderate to high risk of burnout (100\%) which was the highest percentage comparing with the other sections. In depersonalization subscale, radiographers working in $\mathrm{CT}$ section represented the highest proportion with approximately $74 \%$ who were moderate to high risk of burnout. The greatest percentage of moderate to high risk of burnout for personal accomplishment were among radiog- raphers within VIR section with $73 \%$ (see Tables 4-6). By comparing the mean of MBI-HSS subscale scores among sections, US radiographers had the highest risk of burnout for emotional exhaustion with 28.8. CT radiographers showed the greatest risk of burnout for both depersonalization and personal accomplishment with 10.8 and 33.5 respectively (see Figures 1-3). In response to the question about relationship towards workplace, work overload was chosen as the most negative effect toward work by 64 participants $(45 \%)$. Other reasons included unfairness between employees $(29 \%)$ and insufficient rewards (24\%) (see Table 7). 52\% of participants have considered changing specialty, changing hospital or both during the past 12 months (see Table 8). Majority of participants $(63 \%)$ cope with exhaustion feelings by taking a vacation (see Figure 4). The perception of participants about their feelings of burnout was measured by asking them how often they feel burned out from work. $55 \%$ of participants have the feeling of being burned out from work at least once a month. On the other hand, 26\% had that feeling a few times a year or less. Only $19 \%$ of the participants had never felt burned out from work (see Figure 5).

Table 2. Means and standard deviations for subscale scores of radiographers compared to overall sample of Maslach burnout inventory norms

\begin{tabular}{|c|c|c|c|c|}
\hline \multirow[t]{2}{*}{ Sub scale } & \multicolumn{2}{|c|}{$\begin{array}{c}\text { KAMC Sample } \\
\mathbf{N}=\mathbf{1 4 2}\end{array}$} & \multicolumn{2}{|c|}{$\begin{array}{c}\text { MBI Norms Sample } \\
\qquad \mathbf{N}=\mathbf{1 1 , 0 6 7}\end{array}$} \\
\hline & Mean & $S D$ & Mean & $S D$ \\
\hline Emotional Exhaustion & 21.44 & 13.1 & 21.0 & 10.8 \\
\hline Depersonalization & 8.12 & 6.99 & 8.7 & 5.9 \\
\hline Personal Accomplishment & 35.63 & 8.59 & 34.6 & 7.1 \\
\hline
\end{tabular}

Table 3. Interpretation of MBI-HSS subscale scores for radiographers $(\mathrm{N}=142)$

\begin{tabular}{lccc}
\hline \multirow{2}{*}{ Sub scale } & \multicolumn{3}{c}{ N (\%) } \\
\cline { 2 - 4 } & High risk & Moderate risk & Low risk \\
\hline Emotional exhaustion & $51(36)$ & $44(31)$ & $47(33)$ \\
Depersonalization & $38(27)$ & $36(25)$ & $68(48)$ \\
Personal Accomplishment & $37(26)$ & $45(32)$ & $60(42)$ \\
\hline
\end{tabular}

Table 4. Interpretation of emotional exhaustion score for all sections

\begin{tabular}{lccc}
\hline Section & High risk of burnout $\mathbf{n}(\%)$ & Moderate risk of burnout $\mathbf{n}(\%)$ & Low risk of burnout $\mathbf{n}(\%)$ \\
\hline US & $7(64)$ & $4(36)$ & $0(0)$ \\
NM & $4(29)$ & $6(42)$ & $4(29)$ \\
CT & $8(42)$ & $5(26)$ & $6(32)$ \\
VIR & $2(13)$ & $8(54)$ & $5(33)$ \\
X-ray & $25(40)$ & $16(25)$ & $22(35)$ \\
MRI & $5(25)$ & $5(25)$ & $10(50)$ \\
\hline
\end{tabular}


Table 5. Interpretation of depersonalization score for all sections

\begin{tabular}{lccc}
\hline Section & High risk of burnout $\mathbf{n}(\%)$ & Moderate risk of burnout $\mathbf{n}(\%)$ & Low risk of burnout $\mathbf{n}(\%)$ \\
\hline US & $5(46)$ & $2(18)$ & $4(36)$ \\
NM & $2(14)$ & $6(43)$ & $6(43)$ \\
CT & $7(37)$ & $7(37)$ & $5(26)$ \\
VIR & $6(40)$ & $3(20)$ & $6(40)$ \\
X-ray & $17(27)$ & $13(21)$ & $33(52)$ \\
MRI & $1(5)$ & $5(25)$ & $14(70)$ \\
\hline
\end{tabular}

Table 6. Interpretation of personal accomplishment score for all sections

\begin{tabular}{lccc}
\hline Section & High risk of burnout $\mathbf{n}(\boldsymbol{\%})$ & Moderate risk of burnout $\mathbf{n}(\boldsymbol{\%})$ & Low risk of burnout $\mathbf{n}(\boldsymbol{\%})$ \\
\hline US & $3(27)$ & $3(27)$ & $5(46)$ \\
NM & $5(36)$ & $2(14)$ & $7(50)$ \\
CT & $7(37)$ & $5(26)$ & $7(37)$ \\
VIR & $4(27)$ & $7(46)$ & $4(27)$ \\
X-ray & $15(24)$ & $24(38)$ & $24(38)$ \\
MRI & $3(15)$ & $4(20)$ & $13(65)$ \\
\hline
\end{tabular}
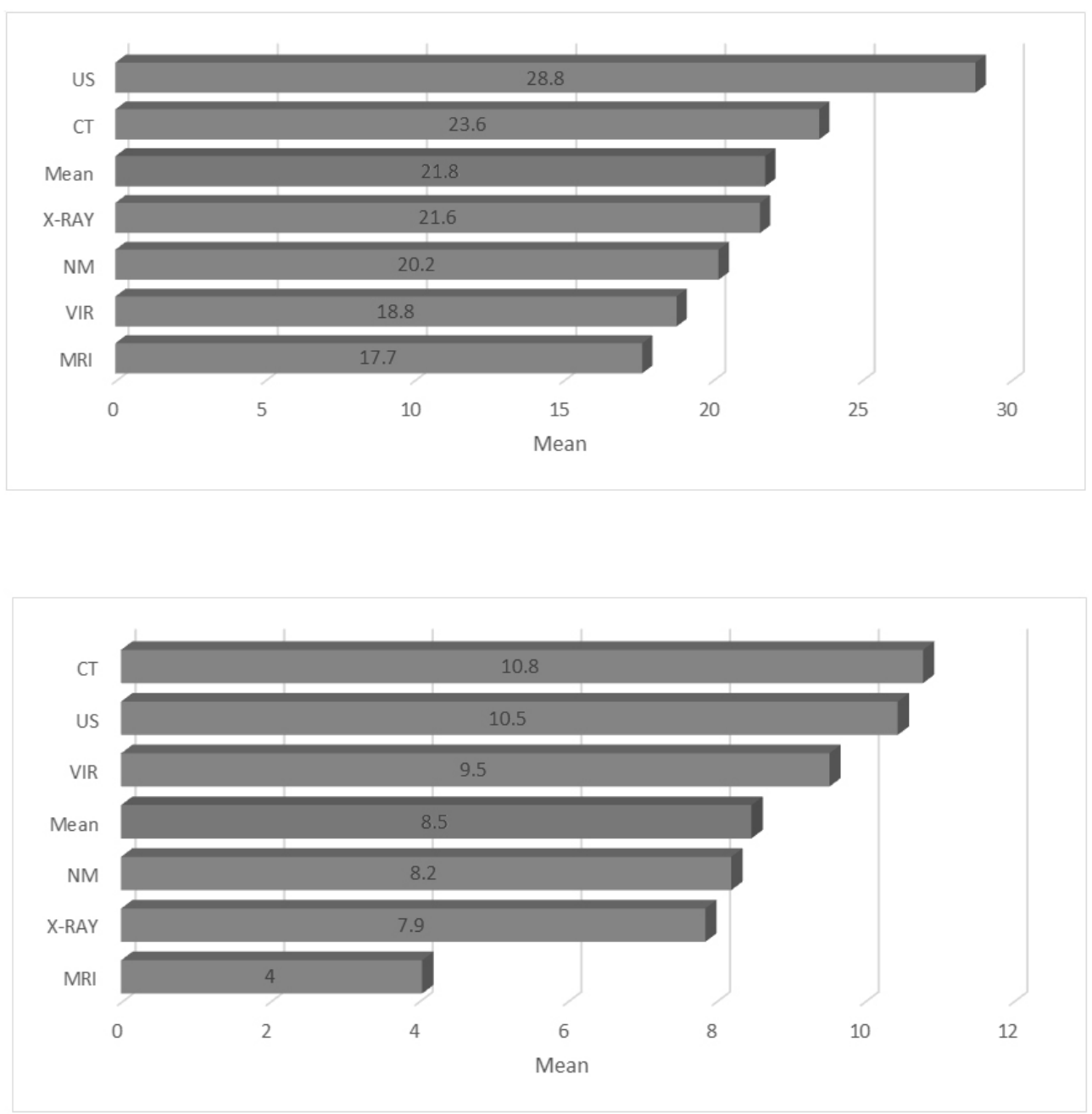

Figure 1. Mean score of emotional exhaustion for all sections

Figure 2. Mean score of depersonalization for all sections 
Figure 3. Mean score of personal accomplishment for all sections

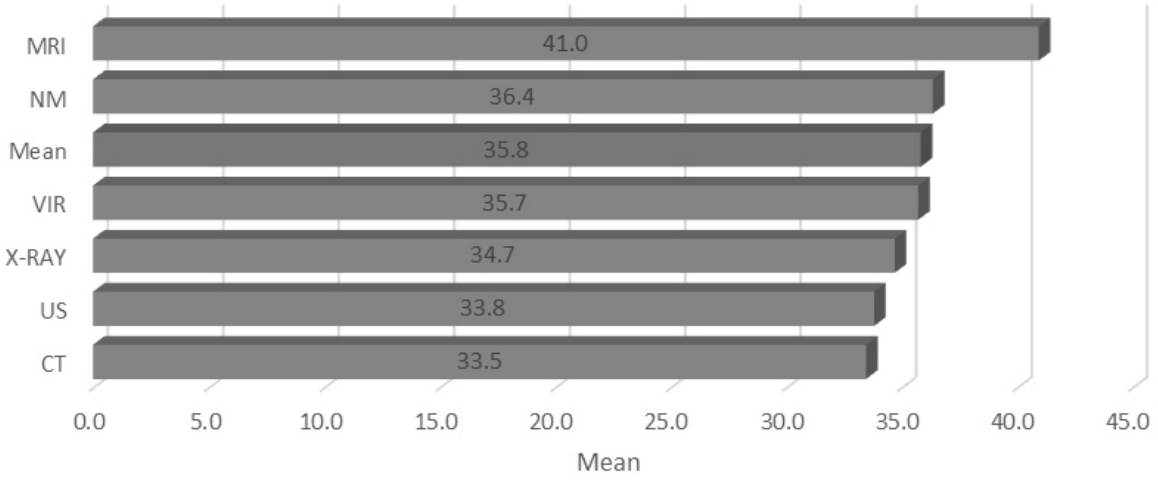

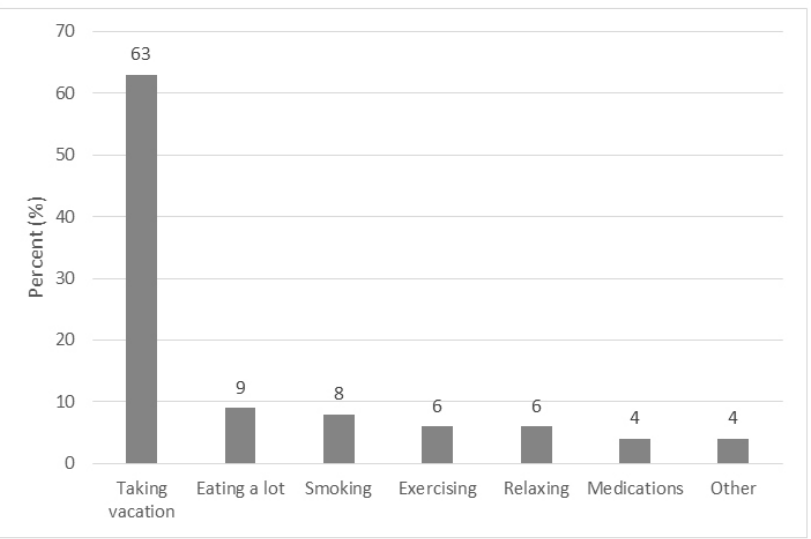

Figure 4. Coping with exhaustion feelings from work

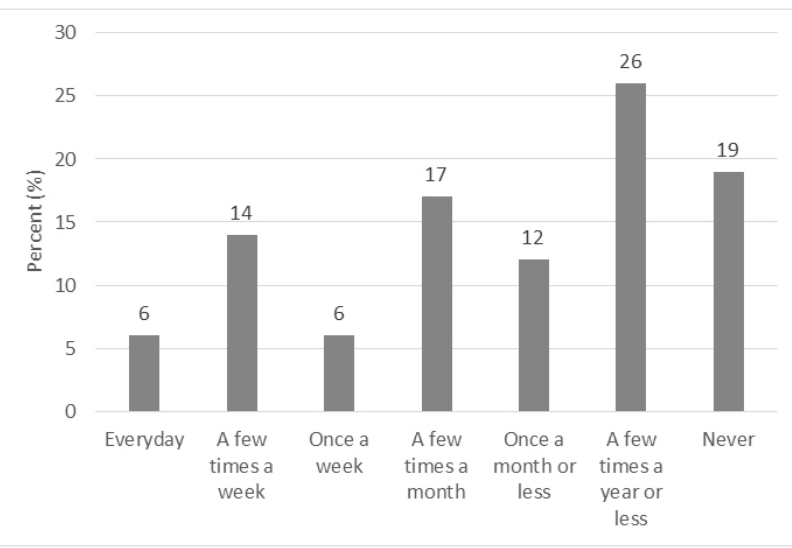

Figure 5. Feeling burned out from work

Table 7. Factors that have the most negative effect on relationship to work place

\begin{tabular}{lc}
\hline Answer & Frequency (\%) \\
\hline Work overload & $64(45)$ \\
Unfairness in dealing with different employees & $40(28)$ \\
Insufficient reward & $34(24)$ \\
Others & $4(3)$ \\
\hline
\end{tabular}

Table 8. Radiographers' responses to the question: Did you consider changing specialty, hospital or both over the last 12 months

\begin{tabular}{lc}
\hline Answer & Frequency (\%) \\
\hline Neither & $68(48)$ \\
Changing both & $33(23)$ \\
Changing the hospital & $23(16)$ \\
Changing the specialty & $18(13)$ \\
\hline
\end{tabular}

\section{Discussion}

To the best of our knowledge, this is the first study conducted in Saudi Arabia that assessed the prevalence of burnout and its risk factors among radiographers. The percentage of radiographers who were at moderate to high risk of burnout for emotional exhaustion, depersonalization and personal accomplishment were $67 \%, 52 \%$ and 58\% respectively. The mean scores were higher than MBI norms for emotional exhaustion and personal accomplishment and lower for depersonalization. The higher than normal score of emotional exhaustion is a key finding since it is considered the core manifestation of burnout. ${ }^{[50]}$ Our study found that US section had the highest percentage of radiographers who were at moderate to high risk of burnout for emotional exhaustion within the sections. We believe that this is because US is an operator-dependent modality that needs to be operated by sonographers which may put more load on sonographers than the other radiographers. A study was done in Australia and New Zealand showed that radiographers within US section had high burnout for emotional exhaustion and depersonalization. The mean emotional exhaustion and depersonalization score among our radiographers within US section were lower than Australia and New Zealand study. ${ }^{[51]}$ In term of depersonalization, CT section had the greatest percentage of radiographers who were at moderate to high risk of burnout within the sections. There are two possible explanations for this. First, CT section deals more with patients from mild to 
severe injuries. Second, due to fast scanning of computed tomography machines, it increases demand load and patients on the radiographers. VIR radiographers represented the highest percentage of radiographers who were at moderate to high risk of burnout for personal accomplishment within the sections. Radiographers within VIR section work as aid to the radiologists who do the procedure. Nature of their work as being aid to the radiologist will make the radiographers feel their work was underappreciated and undervalued. The participants in our study identified work overload as the most negative effect towards work. The radiographers are at consistent pressure due to increased workload, limited resources and poor financial rewards. This is consistent with number of studies that have identified work overload as a major contributor to staff burnout. ${ }^{[52-56]}$

\section{Limitations}

Although this study provided very useful information, it does have limitations that should be addressed in future studies. The main limitations of this study were a limited sample size and being done at a single site.

\section{Conclunsions}

$67 \%$ of radiographers were found to be at moderate to high risk of burnout for emotional exhaustion, $52 \%$ for depersonalization and $58 \%$ for personal accomplishment. Policymakers should take necessary steps to recognize factors contributing to staff burnout and take appropriate steps to improve the work environment.

\section{Conflicts of InTEREST Disclosure}

The authors declare they have no conflicts of interest.

\section{REFERENCES}

[1] Maslach C, Schaufeli WB, Leiter MP. Job burnout. Annual review of psychology. 2001; 52(1): 397-422. PMid: 11148311. https: //doi.org/10.1146/annurev.psych.52.1.397

[2] Bährer-Kohler S. Ed. Burnout for experts: Prevention in the context of living and working. Springer Science \& Business Media; 2012. https://doi.org/10.1007/978-1-4614-4391-9

[3] Schaufeli WB, Bakker AB, Hoogduin K, et al. On the clinical validity of the Maslach Burnout Inventory and the Burnout Measure. Psychology \& Health. 2001; 16(5): 565-582. PMid: 22804499. https://doi.org/10.1080/08870440108405527

[4] Kang EK, Lihm HS, Kong EH. Association of intern and resident burnout with self-reported medical errors. Korean Journal of Family Medicine. 2013; 34(1): 36. PMid: 23372904. https: //doi.org/10.4082/kjfm.2013.34.1.36

[5] Takayesu JK, Ramoska EA, Clark TR, et al. Factors Associated With Burnout During Emergency Medicine Residency. Academic Emergency Medicine. 2014; 21(9): 1031-1035. PMid: 25269584. https://doi.org/10.1111/acem.12464

[6] Dewa CS, Loong D, Bonato S, et al. How does burnout affect physician productivity? A systematic literature review. BMC Health Serv Res. 2014; 14: 325. PMid: 25066375. https ://doi.org/10.118 6/1472-6963-14-325

[7] Yaghmour NA, Brigham TP, Richter T, et al. Causes of Death of Residents in ACGME-Accredited Programs 2000 Through 2014: Implications for the Learning Environment. Acad Med. 2017; 92(7): 976-983. https://doi.org/10.1097/ACM. 0000000000001736

[8] Profit J, Sharek PJ, Amspoker AB, et al. Burnout in the NICU setting and its relation to safety culture. BMJ Qual Saf. 2014; 23(10): 806813. PMid: 24742780 . https://doi.org/10.1136/bmjqs-201 4-002831

[9] Dewa CS, Loong D, Bonato S, et al. The relationship between resident burnout and safety-related and acceptability-related quality of healthcare: a systematic literature review. BMC Med Educ. 2017; 17(1): 195. PMid: 29121895.

[10] Howlett M, Doody K, Murray J, et al. Burnout in emergency department healthcare professionals is associated with coping style: a cross-sectional survey. Emerg Med J. 2015; 32(9): 722-727. PMid:
25604324. https://doi.org/10.1136/emermed-2014-20375 0

[11] O'Gallagher MK, Lewis G, Mercieca K, et al. The impact of the European Working Time Regulations on Ophthalmic Specialist Training-a national trainee survey. International Journal of Surgery. 2013; 11(9): 837-840. PMid: 23994298. https://doi.org/10.1016/j.ijsu .2013 .08 .007

[12] Verhoef LM, Weenink JW, Winters S, et al. The disciplined healthcare professional: a qualitative interview study on the impact of the disciplinary process and imposed measures in the Netherlands. BMJ Open. 2015; 5(11): e009275. PMid: 26608639. https ://doi.or g/10.1136/bmjopen-2015-009275

[13] Gold DR, Rogacz S, Bock N, et al. Rotating shift work, sleep, and accidents related to sleepiness in hospital nurses. American Journal of Public Health. 1992; 82(7): 1011-1014. PMid: 1609900. https://doi.org/10.2105/AJPH.82.7.1011

[14] Dinges DF. An overview of sleepiness and accidents. Journal of Sleep Research. 1995; 4(s2): 4-14. PMid: 10607205. https: //doi.org/10.1111/j.1365-2869.1995.tb00220.x

[15] Efinger J, Nelson LC, Starr JMW. Understanding circadian rhythms: a holistic approach to nurses and shift work. Journal of Holistic Nursing. 1995; 13(4): 306-322. PMid: 8698976. https : //doi .org/10 $.1177 / 089801019501300403$

[16] Newey CA, Hood BM. Determinants of shift-work adjustment for nursing staff: the critical experience of partners. Journal of Professional Nursing. 2004; 20(3): 187-195. https://doi.org/10.101 $6 / j \cdot$ profnurs .2004 .04 .007

[17] Maslach C, Jackson SE, Leiter MP. MBI: Maslach burnout inventory CPP, Incorporated. 1996.

[18] Okwaraji FE, En A. Burnout and psychological distress among nurses in a Nigerian tertiary health institution. African Health Sciences. 2014; 14(1): 237-245. PMid: 26060486. https://doi .org/10.4 314/ahs.v14i1.37

[19] Ribeiro VF, Ferreira Filho C, Valenti VE, et al. Prevalence of burnout syndrome in clinical nurses at a hospital of excellence. International Archives of Medicine. 2014; 7(1): 22. PMid: 24860618. https://doi.org/10.1186/1755-7682-7-22 
[20] Mandengue SH, Owona LM, Lobè-Tanga MY, et al. Burnout syndrome among generalist medical doctors of Douala region (Cameroon): Can physical activities be a protective factor? Revue medicale de Bruxelles. 2017; 38(1): 10-15.

[21] Karakose T. An evaluation of the relationship between general practitioners' job satisfaction and burnout levels. Studies on EthnoMedicine. 2014; 8(3): 239-244. https://doi.org/10.1080/09 735070.2014.11917639

[22] Ang SY, Dhaliwal SS, Ayre TC, et al. Demographics and personality factors associated with burnout among nurses in a Singapore tertiary hospital. BioMed Research International. 2016. PMid: 27478835. https://doi.org/10.1155/2016/6960184

[23] Lahana E, Papadopoulou K, Roumeliotou O, et al. Burnout among nurses working in social welfare centers for the disabled. BMC Nursing. 2017; 16(1): 15. PMid: 28344515. https://doi.org/10.1 186/s12912-017-0209-3

[24] Thomas M, Kohli V, Choi J. Correlates of job burnout among human services workers: Implications for workforce retention. J. Soc. \& Soc Welfare. 2014; 41: 69. https ://doi.org/10.1037/t40608-000

[25] Deniz T, Saygun M, Eroğlu O, et al. Effect of exposure to violence on the development of burnout syndrome in ambulance staff. Turkish Journal of Medical Sciences. 2016; 46(2): 296-302. PMid: 27511488. https://doi.org/10.3906/sag-1406-53

[26] Chen S, Lin S, Ruan Q, et al. Workplace violence and its effect on burnout and turnover attempt among Chinese medical staff. Archives of Environmental \& Occupational Health. 2016; 71(6): 330-337. PMid: 26654585. https ://doi.org/10.1080/19338244.2015. 1128874

[27] Porrino J, Mulcahy MJ, Mulcahy H, et al. Emotional wellness of current musculoskeletal radiology fellows. Academic Radiology. 2017; 24(6): 682-693. PMid: 28341410. https ://doi.org/10.1016/j acra. 2016.12.024

[28] Shanafelt TD, Hasan O, Dyrbye LN, et al. Changes in burnout and satisfaction with work-life balance in physicians and the general US working population between 2011 and 2014. Mayo Clinic Proceedings. 2015; 90(12): 1600-1613. PMid: 26653297. https : //doi.org/10.1016/j.mayocp.2015.08.023

[29] Sturman N, Tan Z, Turner J. "A steep learning curve": junior doctor perspectives on the transition from medical student to the healthcare workplace. BMC Medical Education. 2017; 17(1): 92. PMid: 28549459. https://doi.org/10.1186/s12909-017-0931-2

[30] Verdonk P, Räntzsch V, de Vries R, et al. Show what you know and deal with stress yourself: a qualitative interview study of medical interns' perceptions of stress and gender. BMC Medical Education. 2014; 14(1): 96. PMid: 24884583. https://doi.org/10.1186/ 1472-6920-14-96

[31] Wainwright E, Fox F, Breffni T, et al. Coming back from the edge: a qualitative study of a professional support unit for junior doctors. 2017; 17(1): 142. PMid: 28835270. https://doi.org/10.1186/ s12909-017-0978-0

[32] Dyrbye LN, West CP, Satele D, et al. Burnout Among U.S. Medical Students, Residents, and Early Career Physicians Relative to the General U.S. Population. Academic Medicine. 2014; 89(3): 443 451. PMid: 24448053. https ://doi.org/10.1097/ACM. 000000 0000000134

[33] Elbarazi I, Loney T, Yousef S, et al. Prevalence of and factors associated with burnout among health care professionals in Arab countries: a systematic review. BMC Health Serv Res. 2017; 17(1): 491. PMid: 28716142. https://doi.org/10.1186/s12913-017-2319-8

[34] Miyasaki JM, Rheaume C, Gulya L, et al. Qualitative study of burnout, career satisfaction, and well-being among US neurologists in 2016. Neurology. 2017; 89(16): 1730-1738. PMid: 28931640. https ://doi.org/10.1212/WNL.0000000000004526

[35] Agana DF, Porter M, Hatch R, et al. Job Satisfaction Among Academic Family Physicians. Fam Med. 2017; 49(8): 622-625.

[36] Orri M, Revah-Lévy A, Farges O. Surgeons’ Emotional Experience of Their Everyday Practice - A Qualitative Study. PLoS One. 2015; 10(11): e0143763. PMid: 26600126. https://doi.org/10.137 1/journal.pone. 0143763

[37] Çiçeklioğlu M, Öcek ZA, Turk M, et al. The influence of a marketoriented primary care reform on family physicians' working conditions: A qualitative study in Turkey. European Journal of General Practice. 2014; 21(2): 1-6. PMid: 25387227. https://doi.org/ 10.3109/13814788.2014.966075

[38] Schneider S, Kingsolver K, Rosdahl J. Physician Coaching to Enhance Well-being: A Qualitative Analysis of a Pilot Intervention. Explore. 2014; 10(6): 372-379. PMid: 25240635. https://doi .or g/10.1016/j.explore. 2014.08.007

[39] Kushnir T, Greenberg D, Madjar N, et al. Is burnout associated with referral rates among primary care physicians in community clinics? Fam Pract. 2014; 31(1): 44-50. PMid: 24148815. https : //doi.org/10.1093/fampra/cmt060

[40] Petek D, Gajsek T, Ster MP. Work-family balance by women GP specialist trainees in Slovenia: a qualitative study. BMC Med Educ. 2016; 16: 31 .

[41] Beng TS, Chin LE, Guan NC, et al. The Experiences of Stress of Palliative Care Providers in Malaysia. American Journal of Hospice and Palliative Medicineß). 2013; 32(1): 15-28. PMid: 24023263. https://doi.org/10.1177/1049909113503395

[42] Picard J, Catu-Pinault A, Boujut E, et al. Burnout, empathy and their relationships: a qualitative study with residents in General Medicine. Psychology, Health \& Medicine. 2015; 21(3): 354-361. PMid: 26075525. https ://doi.org/10.1080/13548506.2015. 1054407

[43] Turk M, Davas A, Tanik FA, et al. Organizational stressors, workfamily interface and the role of gender in the hospital: Experiences from Turkey. British Journal of Health Psychology. 2013; 19(2): 442458. PMid: 23552100. https ://doi.org/10.1111/bjhp. 12041

[44] Maslach C, Jackson SE. Burnout in health professions: A social psychological analysis. In: Sanders, G.S. and Suls, J., Eds. Social Psychology of Health and Illness, Erlbanm, Hillsdale. 1982; 227-251.

[45] Williams S, Zipp GP, Cahill T, et al. Prevalence of Burnout Among Doctors of Chiropractic in the Northeastern United States. Journal of Manipulative and Physiological Therapeutics. 2013; 36(6): 376384. PMid: 23896167. https ://doi .org/10.1016/j.jmpt. 201 3.05 .025

[46] Daugherty JM. Burnout. Burnout: How Sonographers and Vascular Technologists React to Chronic Stress. Journal of Diagnostic Medical Sonography. 2002; 18(5): 305-312. https ://doi.org/10.1177/ 875647902236840

[47] Mcgowan Y, Humphries N, Burke H, et al. Through doctors eyes: A qualitative study of hospital doctor perspectives on their working conditions. British Journal of Health Psychology. 2013; 18(4): 874-891. PMid: 23480457. https : //doi .org/10.1111/bjhp. 12037

[48] Subirats-Roig C, Flores-Martí P, Bellot-Arcís C, et al. Validation of the Maslach Burnout Inventory-Human Services Survey for Estimating Burnout in Dental Students. Journal of Dental Education. 2016; 80(11): 1368-1375.

[49] Maslach Burnout Inventory (MBI) - Assessments, Tests I Mind Garden [Internet]. Mind Garden. [cited 2019 Jun 27]. Available from: https : //www.mindgarden.com/117-maslach-burnout -inventory 
[50] Alsaawi A, Alrajhi K, Albaiz S, et al. Risk of burnout among emergency physicians at a tertiary care centre in Saudi Arabia. Journal of Hospital Administration. 2014; 3(4). https://doi.org/10.5 430/jha.v3n4p20

[51] Singh N, Knight K, Wright C, et al. Occupational burnout among radiographers, sonographers and radiologists in Australia and New Zealand: Findings from a national survey. Journal of Medical Imaging and Radiation Oncology. 2016; 61(3): 304-310. PMid: 27753281. https://doi.org/10.1111/1754-9485.12547

[52] Graham J, Ramirez A, Field S, et al. Job Stress and Satisfaction Among Clinical Radiologists. Clinical Radiology. 2000; 55(3): 182185. PMid: 10708609. https://doi.org/10.1053/crad. 1999. 0379

[53] Laschinger HKS, Finegan J, Wilk P. Situational and Dispositional Influences on Nurses Workplace Well-being. Nursing Research. 2011;
60(2): 124-131. PMid: 21317827. https://doi.org/10.1097/ NNR. Ob013e318209782e

[54] Hamaideh SH. Burnout, Social Support, and Job Satisfaction among Jordanian Mental Health Nurses. Issues in Mental Health Nursing. 2011; 32(4): 234-242. PMid: 21355758. https ://doi.org/10.3 $109 / 01612840.2010 .546494$

[55] Aiken LH, Clarke SP, Sloane DM, et al. Hospital Nurse Staffing and Patient Mortality, Nurse Burnout, and Job Dissatisfaction. JAMA. 2002; 288(16): 1987-1993. PMid: 12387650. https://doi.org/ 10.1001/jama. 288.16.1987

[56] Kanai-Pak M, Aiken LH, Sloane DM, et al. Poor work environments and nurse inexperience are associated with burnout, job dissatisfaction and quality deficits in Japanese hospitals. J Clin Nurs. 2008; 17(24): 3324-3329. PMid: 19146591. https://doi.org/10.111 $1 / j .1365-2702.2008 .02639 . x$ 